\title{
The progress towards achieving the UNAIDS ambitious viral suppression target among adults living with HIV in South-Western Nigeria
}

\author{
S.O Usman, A.M. Adebanjo, A. Emeh, E. Ogboghodo, B. Akinbinu, C. Udechukwu, J. Ale, C. \\ Akueshi, E. Fatunsi, A. Ariyo, A. Suraju, I. Oguejiofor, M. Tomori, F.E. Owolagba, T. Jolayemi, P. \\ Okonkwo
}

\begin{abstract}
BACKGROUND: In sub-Saharan Africa where genotypic drug resistance testing is rarely performed and poor adherence is blamed for the inability to achieve viral suppression and treatment failure, programmatic approaches to preventing \& handling these are thus essential. Hypothesis tested was antiretroviral therapy adherence effect on viral load outcome. This study was aimed at determining and monitoring HIV/AIDS disease progression using viral load to provide prognostic information and evaluate patients for viral suppression using the World Health Organization (WHO) guideline strategies. METHODS: This study was an observational study of subjects living with HIV already initiated on antiretroviral therapy for at least six months, enrolled in health facilities across Ondo State, South-Western Nigeria, during a 12-month observation period starting October 2018 till September 2019. Quantitative viral load analysis was done using Polymerase Chain Reaction, Roche Cobas Taqman 96 Analyzer. All data were statistically analyzed, using Statistical Package for the Social Sciences (SPSS), with multiple comparisons done using Post Hoc Bonferonni test. RESULTS: A total of 8124 (1947 males \& 6177 females) subjects eligible for the study were recruited. Most of them are in the age range of $35-39$ years, with a mean age of $42.02 \pm 10.88$ years. $7162(88.2 \%) \& 1771$ $(21.8 \%)$ of the subjects had viral suppression of $<1000$ RNA copies per $\mathrm{ml}$ and <20 RNA copies per $\mathrm{ml}$ respectively. The unsuppressed subjects went through enhanced adherence counselling (EAC) for three months and viral load test repeated thereafter. 192 patients who had completed the three sessions of EAC and repeated viral load increased the entire suppression numbers to $7339(90.3 \%) \& 1824(22.5 \%)<1000$ RNA copies per $\mathrm{ml}$ and <20 RNA copies per $\mathrm{ml}$ respectively during the period of observation. ART adherence has significant effect on viral load outcome from the study hypothesis tested. CONCLUSION: Current ART regimen \& HIV treatment enhanced adherence counseling are key to the achieving viral suppression, thus, routine viral load monitoring will ultimately help in HIV/AIDS disease progression follow up and reduce treatment failure tendencies. This will help more patients stay on first line regimen and prolong their life expectancy, indicating that the UNAIDS last 90 target is achievable.
\end{abstract}

Keywords - Adult, Nigeria, suppression, viral load

\section{INTRODUCTION}

In resource-limited settings, where genotypic drug resistance testing is rarely performed and poor adherence is regarded as the most common reason for treatment failure, programmatic approaches to handling treatment failure are essential. HIV viral load is a virological marker of antiretroviral treatment (ART) response and HIV/AIDS disease progression used to manage and monitor the infection in patients living with virus. The magnitude of the viral load after ART initiation provides prognostic information about the disease progression. The key goal of ART is to achieve and maintain durable viral suppression. Optimal viral suppression is defined generally as a viral load persistently below the level of detection $[1,2,3]$. The guidelines of the World Health Organization (WHO) for the treatment of Human Immunodeficiency Virus (HIV) infection recommend that, where possible, the viral load of individuals receiving ART be measured every month to detect viral replication and confirm treatment failure whenever it occurs [4]. According to the WHO's strategy for the surveillance and monitoring of HIV drug resistance in Low \& Middle Income Countries (LMICs), a viral load of $<1000$ RNA copies per ml should be taken as evidence of viral suppression [5].

According to a study in Botswana from Harvard T.H Chan school of Public Health \& Colleagues, Botswana was reported to have achieved very high rates of HIV diagnosis, treatment and viral suppression, even much better than most Western Nations. The country was reported to achieve have 3596 (29\%) infected with HIV and 2995 (83.3\%) of these individuals already have their HIV status known. Among them, 2617 (87.4\%) were receiving ART and out of the 2609 people receiving ART who had their viral load checked, 2517 (96.5\%) had viral suppression [6]. In another 2016 research, 78.5\% of HIV patients in care are reported to have a suppressed viral load based on a single test while $65.9 \%$ were virally suppressed based on a minimum of two or more rounds of test done [7]. In a 2015 study carried out on the scale- up of HIV viral load monitoring across seven SubSaharan African countries revealed that South Africa, for instance, initiated viral load monitoring in 2004 and scale up for routine viral load monitoring in 2014 on the basis of the 2013 WHO HIV treatment recommendations, while countries such as Kenya, Malawi, Namibia and Uganda, had their scale-up mostly between 2014 to 2015. Cote d'voire and Tanzania had theirs in 2015. Thus, the proportion of viral load monitoring scale up was $78 \%$ in South Africa, $83 \%$ in Kenya, $84 \%$ in Malawi, $86 \%$ in Namibia, $94 \%$ in Uganda, $53 \%$ in Cote d'voire and $72 \%$ in Tanzania [8]. In another Uganda study, $6 \%$ of the patients were reported to have experienced virological failure, which was defined as two consecutive viral loads $>500$ copies $/ \mathrm{ml}$ occurring more than three months after the start of ART [9]. A 2017 study on the 90-90-90 
ambitious targets in Western Nigeria revealed that 787 $(86.5 \%)$ of the subjects had viral suppression of $<1000$ RNA copies per $\mathrm{ml}$ during the period of observation after extensive adherence counselling [10]. This study was aimed at determining and monitoring HIV/AIDS disease progression using viral load to provide prognostic information and evaluate adult patients living with HIV for viral suppression using the World Health Organization (WHO) guideline strategies.

\section{RESEARCH HYPOTHESIS} Antiretroviral (ARV) therapy adherence does not
significantly have impact on viral load outcome.

\section{METHODS}

This study was an observational study of adult patients living with HIV already initiated on antiretroviral (ARV) therapy for at least six months enrolled at various primary, secondary and tertiary level hospitals across Ondo State in South-Western Nigeria, during a 12-month observation period starting October 2018 to September 2019. The study population was adult patients living with HIV already initiated on antiretroviral (ARV) therapy for at least six months. The viral load samples were analysed with an automated real-time amplification and detection of RNA using a quantitative RNA polymerase chain reaction (PCR) analyser by (Roche Molecular Diagnostics, Basel, Switzerland). Relevant data such as age, sex, functional status, WHO clinical staging, ARV regimen at start and current, ARV adherence level, among others were obtained and analysed.

Ethical approval was sought and obtained from the Ethics \& Research Committee, Federal Teaching Hospital, Ido Ekiti, Nigeria. The data analysis was done using statistical package for the social sciences (SPSS) for windows version 23.0 software (SPSS Inc; Chicago, IL, USA). Frequency counts were generated for all variables and statistical test of significance was performed with chi-square test. Other data were expressed as Mean \pm Standard Deviation and analysed with chi square test. Significance was fixed at $\mathrm{P}<0.05$.

\section{RESULTS}

\section{SOCIO-DEMOGRAPHIC DATA}

A total of 8124 subjects eligible for the study were recruited. Most of them are in the age range of $35-39$ years, with a mean age \pm SD of $42.02 \pm 10.88$ years. The mean number of years the patients have been on ART regimen is $4.94 \pm 2.93$ years. $4109(50.6 \%)$ were recruited from tertiary hospitals, $3412(42.0 \%)$ were from secondary facilities while $603(7.4 \%)$ were recruited from primary healthcare facilities.

All the subjects are active on antiretroviral treatment. Using the WHO strategy, those having viral load $<1000$ RNA copies per ml, were 7162 (88.2\%), out of which 1771 (21.8\%) had viral load <20 RNA copies per ml. The unsuppressed subjects went through enhanced adherence counselling (EAC) for three months and viral load test repeated thereafter. 192 patients who had completed the three sessions of EAC and repeated viral load increased the entire suppression numbers to $7339(90.3 \%)$ \& $1824(22.5 \%)<1000$ RNA copies per $\mathrm{ml}$ and $<20$ RNA copies per $\mathrm{ml}$ respectively during the period of observation.

At the commencement of ART, 5338 (65.7\%) patients that commenced tenofovir, lamivudine \& efavirenz (TLE) regimen, $3424(64.1 \%)$ transitioned to tenofovir, lamivudine \& dolutegravir (TLD), with $1182(34.5 \%)$ being male and $2242(65.5 \%)$ being female. $2200(98.1 \%)$ of the patients are not pregnant while $42(1.9 \%)$ are pregnant. In viral suppression comparison, 1757 patients who commenced on tenofovir, lamivudine \& efavirenz (TLE) regimen and are still on that regimen, had $1546(88.0 \%)$ virally suppressed while 339 patients that commenced on tenofovir, lamivudine \& dolutegravir (TLD) and still on the regimen, had 293 (86.4\%) virally suppressed.

\section{SOCIO-DEMOGRAPHIC \& TREATMENT DATA}

\begin{tabular}{|l|l|}
\hline VARIABLES & Frequency (\%) \\
\hline Age Group (years) & $102(1.3)$ \\
\hline $15-19$ & $208(2.6)$ \\
$20-24$ & $524(6.5)$ \\
$25-29$ & $1172(14.4)$ \\
$30-34$ & $1602(19.7)$ \\
$35-39$ & $1516(18.7)$ \\
$40-44$ & $1159(14.3)$ \\
$45-49$ & $777(9.6)$ \\
$50-54$ & $507(6.2)$ \\
$55-60$ & $557(6.9)$ \\
$\geq 60$ & $1947(24.0)$ \\
\hline Sex & $6177(76.0)$ \\
\hline Male & $4109(50.6)$ \\
Female & $3412(42.0)$ \\
\hline Hospital Facility & $603(7.4)$ \\
\hline Tertiary & $5338(65.7)$ \\
Secondary & $339(4.2)$ \\
Primary & $17(0.2)$ \\
\hline Antiretroviral Therapy (ART) taken at start of treatment \\
\hline Tenofovir, Lamivudine \& Efavirenz & $2373(29.2)$ \\
Tenofovir, Lamivudine \& Dolutegravir & $6(0.1)$ \\
Zidovudine, Lamivudine \& Efavirenz & $10(0.1)$ \\
Zidovudine, Lamivudine \& Nevirapine & $28(0.3)$ \\
Abacavir, Lamivudine \& Efavirenz & $13(0.2)$ \\
Tenofovir, Lamivudine \& Atazanavir/Ritonavir & \\
Tenofovir, Lamivudine \& Lopinavir/Ritonavir & \\
Zidovudine, Lamivudine \& Lopinavir/Ritonavir & \\
\hline
\end{tabular}

\section{SOCIO-DEMOGRAPHIC \& TREATMENT DATA}

\begin{tabular}{|c|c|}
\hline VARIABLES & Frequency $(\%)$ \\
\hline \multicolumn{2}{|l|}{ Antiretroviral Therapy (ART) currently used } \\
\hline Tenofovir, Lamivudine \& Efavirenz & $2482(30.6)$ \\
\hline Tenofovir, Lamivudine \& Dolutegravir & $5241(64.5)$ \\
\hline Zidovudine, Lamivudine \& Nevirapine & $17(0.2)$ \\
\hline Abacavir, Lamivudine \& Efavirenz & $13(0.2)$ \\
\hline Tenofovir, Lamivudine \& Atazanavir/Ritonavir & $74(0.9)$ \\
\hline Tenofovir, Lamivudine \& Lopinavir/Ritonavir & $170(2.1)$ \\
\hline Zidovudine, Lamivudine \& Atazanavir/Ritonavir & $8(0.1)$ \\
\hline Zidovudine, Lamivudine \& Lopinavir/Ritonavir & $119(1.5)$ \\
\hline \multicolumn{2}{|l|}{ Antiretroviral Therapy (ART) Adherence } \\
\hline Fair $(85-94 \%) /(4-8$ doses missed per month $)$ & $697(8.6)$ \\
\hline Good $(\geq 95 \%) /(\leq 3$ doses missed per month $)$ & $7427(91.4)$ \\
\hline \multicolumn{2}{|l|}{ Number of years active on treatment } \\
\hline 1 year & $891(11.0)$ \\
\hline 2 years & $1210(14.9)$ \\
\hline 3 years & $1126(13.9)$ \\
\hline 4 years & $830(10.2)$ \\
\hline 5 years & $798(9.8)$ \\
\hline 6 years & $836(10.3)$ \\
\hline 7 years & $811(10.0)$ \\
\hline 8 years & $418(5.1)$ \\
\hline 9 years & $453(5.6)$ \\
\hline 10 years & $403(5.0)$ \\
\hline 11 years & $234(2.9)$ \\
\hline
\end{tabular}




\begin{tabular}{|l|l|}
\hline 12 years & $98(1.2)$ \\
13 years & $10(0.1)$ \\
14 years & $6(0.1)$ \\
\hline
\end{tabular}

Chi square result showing influence of ARV therapy adherence on viral load outcome

\begin{tabular}{llccc} 
VARIABLES & $\boldsymbol{\chi}^{\mathbf{2}}$ & df & Critical value & Decision \\
\hline $\begin{array}{l}\text { ARV therapy } \\
\text { adherence influence } \\
\text { on viral load outcome }\end{array}$ & 7.63 & 1 & 3.84 & Rejected \\
& & & &
\end{tabular}

The null hypothesis is rejected when the test statistic $\left(\chi^{2}\right)$ is greater than the critical value.

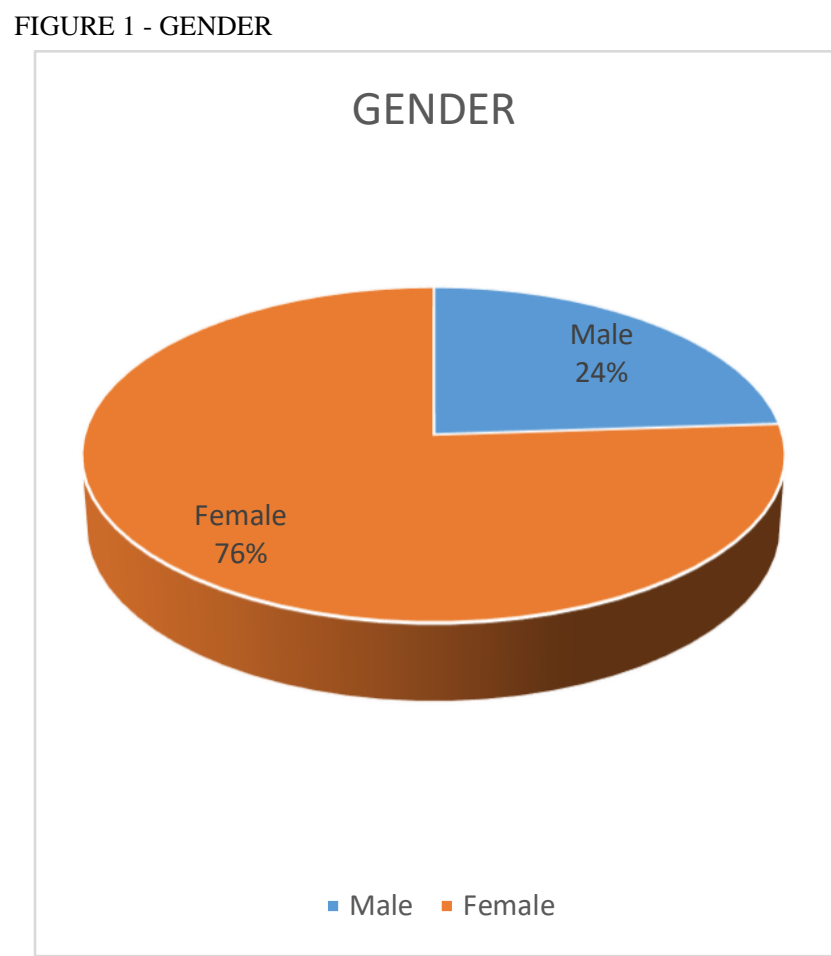

FIGURE 1I - VIRAL LOAD OUTCOME

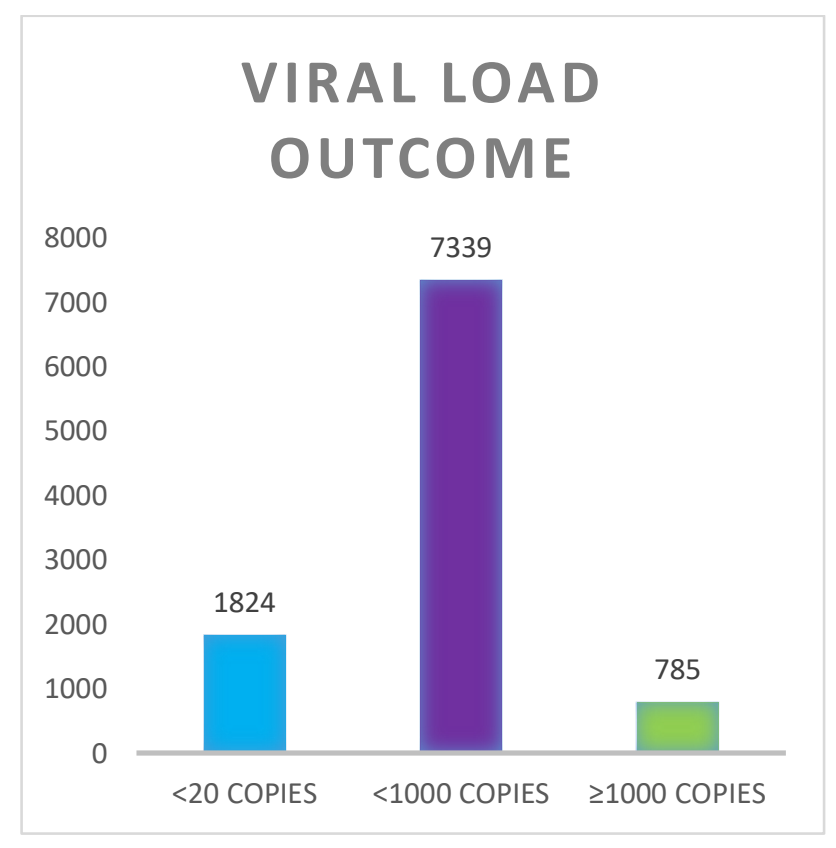

FIGURE 1II - COMPARISON OF SUPPRESSION RATE BEFORE AND AFTER EAC

\section{Suppression Rate Pre \& Post-EAC}

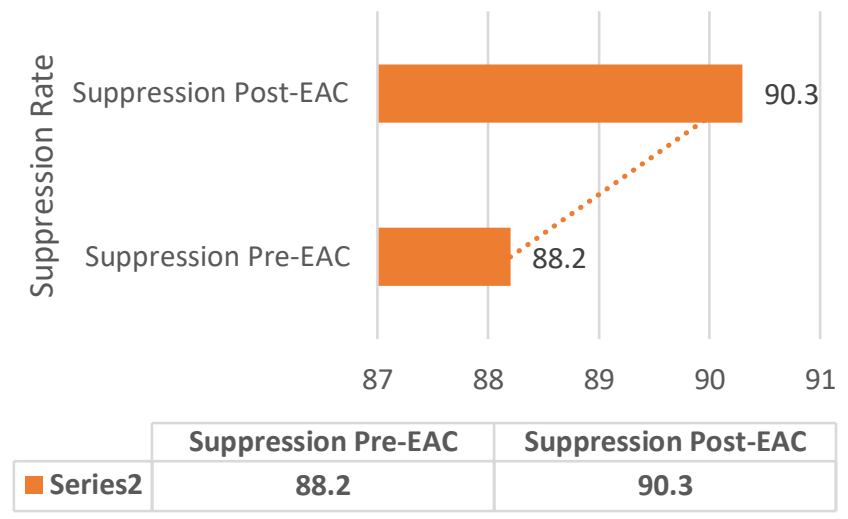

FIGURE 1V - PREGNANCY STATUS OF FEMALE SUBJECTS

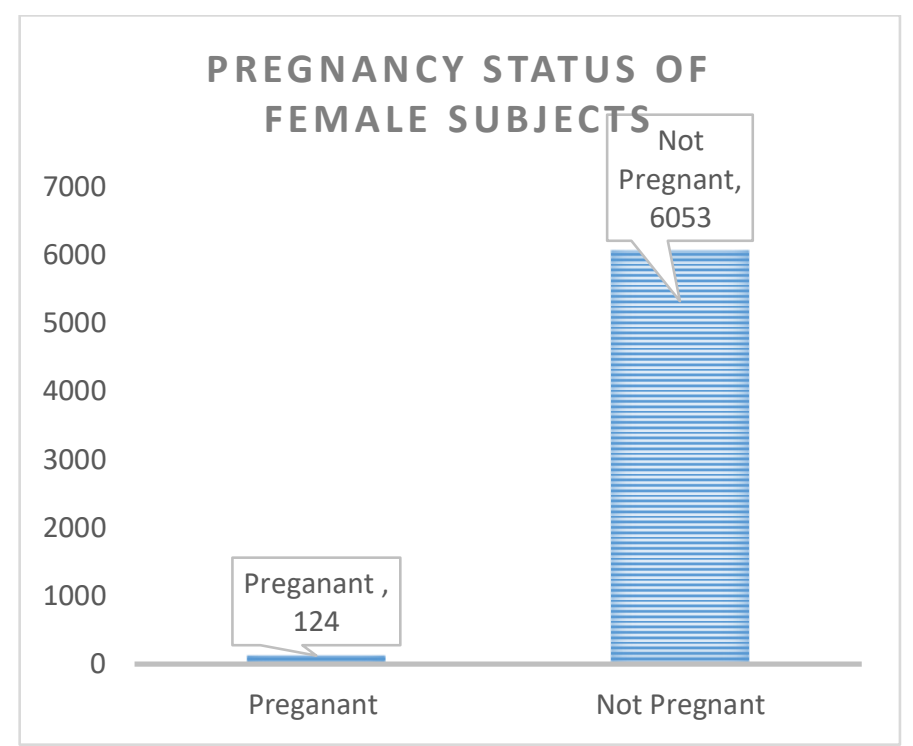

FIGURE V - CURRENT ART REGIMEN OF PREGNANT WOMEN

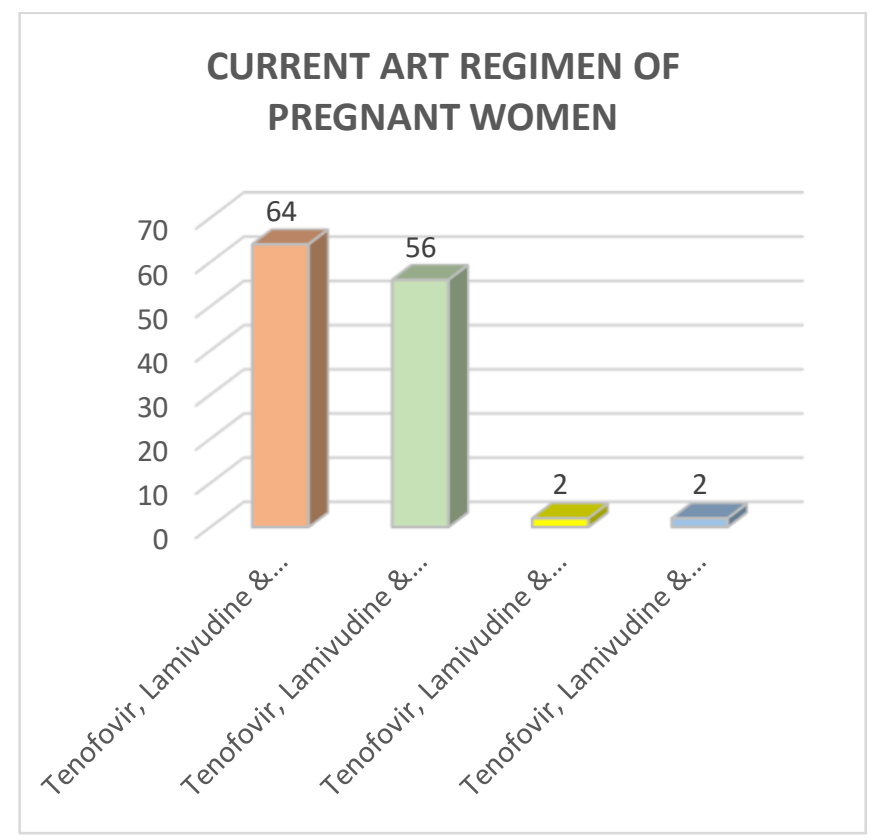




\section{DISCUSSION}

The outcome of this research reveals that $88.2 \%$ of the patients had suppressed viral load based on the viral load outcome using the WHO's strategy for surveillance and monitoring of HIV drug resistance in Low \& Middle Income Countries (LMICs), which indicated that a viral load of $<1000$ RNA copies per ml should be taken as evidence of viral suppression [5]. The unsuppressed viral load went through three sessions of enhanced adherence counseling (EAC) for three months and viral load test repeated thereafter. This adherence counselling process increased the virally suppressed to $90.3 \%$ based on all tests done during the period of observation. Meanwhile, in comparison with high-income countries where the guidelines stipulate that a viral load of $<50$ RNA copies per ml or a load below the limit of detection of the most sensitive assay available, be taken as evidence of viral suppression $[11,12,13]$. These outcomes are slightly similar to a study that reported $78.5 \%$ viral suppression [7], $86.5 \%$ viral suppression report in Western Nigeria [10] but differ slightly from a Botswana study that reported $96.5 \%$ viral suppression [6]. This generally however shows that more subjects exhibited improvement, as they went from unsuppressed to suppressed status, within a short period of adequate drug adherence. The enhanced adherence counselling is thus essential in ART and the accessibility to every unsuppressed patient is key, which include adherence assessments and documentation at every clinic visit, with emphasis on the importance of continued adherence and involvement of support systems, adverse drug reactions, among others.

At the commencement of ART, $5338(65.7 \%)$ patients that commenced tenofovir, lamivudine \& efavirenz (TLE) regimen, $3424(64.1 \%)$ transitioned to tenofovir, lamivudine \& dolutegravir (TLD), which is in line with the new direction of patient management in the country, with TLD being the first line regimen of choice. In viral suppression comparison, 1757 patients who commenced on tenofovir, lamivudine \& efavirenz (TLE) regimen and are still on that regimen, had $1546(88.0 \%)$ virally suppressed while 339 patients that commenced on tenofovir, lamivudine \& dolutegravir (TLD) and still on the regimen, had $293(86.4 \%)$ virally suppressed. This shows no significant difference in viral suppression strength in both regimen, though, the number of patients compared are not commensurate.

Meanwhile, with majority of the patients currently on first line regimen, mainly of the combinations Tenofovir, Lamivudine \& Dolutegravir (TLD), having < 1000 RNA copies per ml, may be an indication for treatment success for this particular regimen in majority of the patients on the regimen. Moreover, the rejection of the tested hypothesis on the influence of ARV therapy adherence on viral load outcome, indicates that drug adherence significantly determines outcome of viral load, evident by the ART adherence of all subjects with $<1000$ RNA copies per ml having $\geq 95 \%$ (good) drug adherence, which shows that they have either not missed any dose or few missed $\leq 3$ doses, also indicating treatment success. This is a positive development with the TLD regimen being adhered to better as it is also being taken once daily at typically convenient time, with possible fewer side effects felt by the patients.

\section{CONCLUSION}

HIV treatment enhanced adherence counseling is key to the achieving viral suppression and determine infection prognosis, thus, routine viral load monitoring will ultimately help in HIV/AIDS disease progression follow up and reduce treatment failure tendencies. This will help more patients stay on first line regimen and prolong their life expectancy, indicating that the UNAIDS last 90 target is achievable.

\section{ACKNOWLEDGEMENTS}

Our sincere appreciation goes to all participants that took part in this study.

\section{FINANCIAL \& NON-FINANCIAL COMPETING INTEREST}

The authors declare no financial or non-financial competing interest.

\section{CONFLICT OF INTEREST}

Authors declare they have no conflict of interest.

\section{REFERENCES}

[1] H. Gatanaga, K. Tsukada, H. Honda, J. Tanuma, H. Yazaki, T. Watanabe, M. Honda, K. Teruya, Y. Kikuchi and S. Oka (2009) 'Detection of HIV Type 1 Load by the Roche Cobas TaqMan Assay in Patients with Viral Loads Previously Undetectable by the Roche Cobas Amplicor Monitor', Clinical infectious diseases, pp. $259-60$. doi: 10.1086/595706.

[2] J.H. Willig, C.R. Nevin, J.L. Raper, M.S. Saag, M.J. Mugavero, A.L. Willig, J.H. Burkhardt, J.E. Schumacher and V.A. Johnson (2010). 'Cost Ramifications of Increased Reporting of Detectable Plasma HIV-1 RNA Levels by the Roche COBAS AmpliPrep/COBAS TaqMan HIV-1 Version 1.0 Viral Load Test', JAIDS Journal of Acquired Immune Deficiency Syndromes, 54(4), pp. 442-443. doi: 10.1097/QAI.0b013e3181d01d1d.

[3] R.L. Hamers, C. Kityo, J.M.A. Lange, T.F.R Wit and p. Mugyenyi (2012). 'Global threat from drug resistant HIV in sub-Saharan Africa', BMJ, 344, pp. e4159-e4159. doi: 10.1136/bmj.e4159.

[4] World Health Organization (WHO). Antiretroviral therapy for HIV infection in adults and adolescents: recommendations for a public health approach, Geneva. 2010.

[5] D.E. Bennett, S. Bertagnolio, D. Sutherland and C.F. Gilks (2008). 'The World Health Organization's global strategy for prevention and assessment of HIV drug resistance', Antiviral Therapy, pp. 1-13.

[6] T. Gaolathe, K.E. Wirth, M.P. Holme, J. Makhema, S. Moyo, U. Chakalisa, E.K. Yankinda, Q. Lei, M. Mmalane, V. Novitsky, L. Okui, Q. van Widenfelt, K.M. Powis, N. Khan, K. Bennett, H. Bussmann, S. Dryden-Peterson, R. Lebelonyane, S. el-Halabi, L.A. Mills, T. Marukutira, R.Wang, E.J.T. Tchetgen, V. DeGruttola, M. Essex and S. Lockman (2016). 'Botswana's progress toward achieving the 2020 UNAIDS 90-90-90 antiretroviral therapy and virological suppression goals: A population-based survey', The Lancet HIV, 3(5), pp. e221e230. doi: 10.1016/S2352-3018(16)00037-0.

[7] G. Marks, U. Patel, M.J. Stirratt, M.J. Mugavero, W.C. Mathews, T.P Giordano, N. Crepaz, L.I. Gardner, C. Grossman, J. Davila, M Sullivan, C.E. Rose, C. O’Daniels, A. Rodriguez, A.J. Wawrzyniak, M.R. Golden, S. Dhanireddy, J. Ellison, M.L. Drainoni, L.R. Metsch and E.R. Cachay (2016). 'Single Viral Load Measurements Overestimate Stable Viral Suppression among HIV Patients in Care: Clinical and Public Health Implications.', Journal of acquired immune deficiency syndromes (1999), 73(2), pp. 205-212. doi: 10.1097/QAI.0000000000001036.

[8] S. Lecher, D. Ellenberger, A.A. Kim, P.N. Fonjungo, S. Agolory, M.Y. Borget, L. Broyles, S. Carmona, G. Chipungu, K.M. De Cock, 
V. Deyde, M. Downer, S. Gupta, J.E. Kaplan, C. Kiyaga, N. Knight, W. MacLeod, B. Makumbi, H. Muttai and C. Mwangi (2015). 'Scaleup of HIV Viral Load Monitoring - Seven Sub-Saharan African Countries.', MMWR: Morbidity \& Mortality Weekly Report, 64 (46), pp. $1287-1290$.

[9] J. Mermin, J.P. Ekwaru, W. Were, R. Degerman, R. Bunnell, F. Kaharuza, R. Downing, A. Coutinho, P. Solberg, L.N. Alexander, J. Tappero, J. Campbell and D.M. Moore (2011). 'Utility of routine viral load, CD4 cell count, and clinical monitoring among adults with HIV receiving antiretroviral therapy in Uganda: randomised trial.', BMJ (Clinical research ed.), 343(7834), p. d6792. doi: 10.1136/bmj.d6792.

[10] S.O. Usman, O. Oluawniyi, G.P. Olubayo, T. Akinmurele, G.B. Agboola, F. Abodunde, A. Afe, O. Adeola and M. Onyema (2017). 90-90-90 Ambitious targets: achieving the last 90 of the UNAIDS targets in Western Nigeria. International STD Research \& Reviews, 6(2): 1-9.

[11] M.A. Thompson, J.A. Aberg, P. Cahn, J.S.G. Montaner, G. Rizzardini, A. Telenti, J.M. Gatell, H.F. Günthard, S.M. Hammer, M.S. Hirsch, D.M. Jacobsen, P. Reiss, D.D. Richman, P.A Volberding, P. Yeni and R.T. Schooley (2010) 'Antiretroviral treatment of adult HIV infection: 2010 recommendations of the International AIDS Society-USA panel.', JAMA : the journal of the American Medical Association, 304(3), pp. 321-333. doi: 10.1001/jama.2010.1004.

[12] D. Asboe, C. Aitken, M. Boffito, C. Booth, P. Cane, A. Fakoya, A.M. Geretti, P. Kelleher, N. Mackie, D. Muir, G. Murphy, C. Orkin, F. Post, G. Rooney, C. Sabin, L. Sherr, E. Smit, W. Tong, A Ustianowski, M. Valappil, J. Walsh, M. Williams and D. Yirrell (2012). 'British HIV Association guidelines for the routine investigation and monitoring of adult HIV-1-infected individuals 2011', HIV Medicine, 13(1), pp. 1-44. doi: 10.1111/j.14681293.2011.00971.x.

[13] Panel on Antiretroviral Guidelines for Adults \& Adolescents (PAGAA) (2012). Guidelines for the use of antiretroviral agents in HIV-1 infected adults and adolescents. Washington: Department of Health and Human Services.

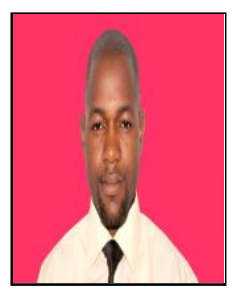

Saheed Usman is an efficient \& resourceful award winning health professional, researcher \& scholar with over ten years' experience in laboratory medicine \& public health intervention programs implementation health system strengthening programs for control of infectious and noncommunicable diseases. He has several publications in reputable local \& international journals, presentations at various clinical \& laboratory conferences \& congresses, with travel grants \& scholarships from various international organizations. Currently, Saheed is a Technical Officer at APIN Public Health Initiatives, Abuja, Nigeria. 